\title{
KONSEP DESAIN HOTEL RESORT BERIDENTITAS BALI DI PANTAI BUGBUG, KARANGASEM - BALI
}

\author{
I Gede Ramsa Wahyu Alam Sari ${ }^{1}$, I Wayan Runa², Ni Wayan Meidayanti Mustika ${ }^{3}$ \\ ${ }^{1}$ Mahasiswa Program Studi Arsitektur, Universitas Warmadewa, Bali \\ ${ }^{2,3}$ Program Studi Arsitektur, Universitas Warmadewa - Bali \\ 1e-mail: ramsawahyu28@gmail.com
}

How to cite (in APA style):

Sari, I G. R. W. A., Runa, I W. \& Mustika, Ni W. M. (2020). Konsep Desain Hotel Resort Beridentitas Bali di Pantai Bugbug, Karangasem - Bali. Undagi : Jurnal Ilmiah Jurusan Arsitektur Universitas Warmadewa. Volume (Issue), pp.31-36.

\begin{abstract}
This tourism accommodation was built aimed at equitable development of hotels that lead to east, north and west Bali. Due to the development gap between the construction of tourism facilities which will be concentrated in South Bali, it is necessary to equalize other areas of Bali such as east, west and north Bali. It also aims to develop regional income as a domestic and foreign tourist destination. The data collection methods used are, for example, the literature study method, which is the data collection method carried out by taking the necessary data from the related literatures. Either that is done by making direct observations in the field, regarding the problem being reviewed. By jumping directly to the location and see the physical condition of the area itself. As well as documentation methods, namely taking pictures to strengthen and clarify theoretical data by taking photos directly to the object. The concept of site planning will refer to the east-west oriented spatial concept. Its implementation will form the main, intermediate and blasphemous area values. Both the concept as the rising and setting of the sun and the north south associated with mountains and the sea in zoning arrangement, the layout of the entrance or entrance, the basic form of mass, mass system, mass patterns that will produce the orientation of the mass of the building, circulation and outer space. The concept of building planning where in this concept the shape of the building of the resort hotel has almost been realized in the form of the concept of interior space or called the interior of the building that displays the dimensions of the space, material and function of the space itself, where the inner space will produce the appearance of the building or face of the facade the exterior of this resort hotel The utility system concept is not spared from buildings like humans as a container for utility buildings as a channel for the nerves of human channels or buildings so that the utility system cannot be separated from being linked to the building as for the utility system which later as a basic reference for the construction of this resort hotel or as a distribution of development tourism and increase the original income of the region especially Karangasem Regency.
\end{abstract}

Keywords: Modern Tropical; Recreation; Resort Hotels

\begin{abstract}
ABSTRAK
Tujuan perencanaan dan perancangan Hotel Resort ini adalah untuk mengembangkan hotel yang adil yang mengarah ke timur, utara dan barat Bali. Karena kesenjangan pembangunan antara pembangunan fasilitas pariwisata yang akan terkonsentrasi di Bali Selatan, maka perlu untuk menyamakan daerah lain di Bali seperti Bali timur, barat dan utara. Ini juga bertujuan untuk mengembangkan pendapatan daerah sebagai tujuan wisata domestik dan asing. Metode pengumpulan data yang digunakan adalah, metode studi literatur, yang merupakan metode pengumpulan data yang dilakukan dengan mengambil data yang diperlukan dari literatur terkait. Entah itu dilakukan dengan melakukan pengamatan langsung di lapangan, mengenai masalah yang sedang ditinjau. Dengan melompat langsung ke lokasi dan melihat kondisi fisik daerah itu sendiri. Serta metode dokumentasi, yaitu mengambil gambar untuk memperkuat dan memperjelas data teoritis dengan mengambil foto langsung ke objek. Konsep perencanaan lokasi akan mengacu pada konsep tata ruang berorientasi timur-barat. Implementasinya akan membentuk nilai-nilai area utama, menengah dan transparan. Baik konsep sebagai terbit dan terbenamnya matahari dan utara selatan dihubungkan dengan gunung dan laut dalam pengaturan zonasi, tata letak pintu masuk
\end{abstract}


atau pintu masuk, bentuk dasar massa, sistem massa, pola massa yang akan menghasilkan orientasi dari massa bangunan, sirkulasi dan ruang angkasa. Konsep perencanaan bangunan dimana dalam konsep ini bentuk bangunan resort hotel telah hampir diwujudkan dalam bentuk konsep ruang interior atau disebut interior bangunan yang menampilkan dimensi ruang, bahan dan fungsi dari ruang itu sendiri, di mana ruang dalam akan menghasilkan penampilan bangunan atau wajah fasad eksterior resor hotel ini. Konsep sistem utilitas tidak luput dari bangunan seperti manusia sebagai wadah untuk bangunan utilitas sebagai saluran untuk saraf saluran manusia atau bangunan sehingga sistem utilitas tidak dapat dipisahkan dari yang terhubung ke bangunan seperti untuk sistem utilitas yang kemudian sebagai referensi dasar untuk pembangunan resor hotel ini atau sebagai distribusi pengembangan pariwisata dan meningkatkan pendapatan asli dari wilayah khususnya Kabupaten Karangasem

Kata kunci: Hotel Resor; Rekreasi; Tropis modern

\section{PENDAHULUAN}

Bali tidak saja Bali selatan, tidak saja Kabupaten Badung, juga ada wilayah belahan utara, timur dan belahan barat yang memang saat ini pelaksanaan pembangunannya belum merata, atau belum adil, menurut data PHRI atau Perhimpunan Hotel dan Restoran Indonesia, Bali memiliki 2079 Hotel yang tersebar di seluruh Bali. Kenjangan tersebut karena pembangunan fasilitas pariwisata yang terkonsentrasi di Bali Selatan (Wijaya \& Kunci, 2015). Propinsi Bali terdiri dari 8 kabupaten seperti: Kabupaten Badung, Tabanan Jembrana, Buleleng, Gianyar, Bangli, Kelungkung, Karangasem dan 1 kota madya yaitu Denpasar. Setiap wilayah sudah tentu memiliki potensi dan karakteristik kawasan yang berbeda beda, sehingga dibutuhkan penataan secara spesifik untuk pemerataan pembangunan Hotel pariwisata di Bali sehingga dapat dilaksanakannya pembangunan secara merata seperti apa yang diharapkan.

Kecamatan Karangasem terbagi menjadi 11 desa, seperti : Desa Bugbug, akan tetapi keberadaan fasilitas wisata saat ini masih belum memadai dan perlu penataan kawasan secara matang untuk dapat menarik wisatawan. Untuk detailnya pada area Pantai Pasih Kelod Desa Bugbug dengan pertimbangan memilih lokasi ini ditinjau dari yang termasuk zona kawasan pariwisata yang telah ditetapkan oleh kabupaten karangasem dilihat dari potensi seperti menjadi kawasan wisata yang terletak di
Desa Bugbug Karangasem. Hanya saja pada bagian-bagian tertentu belum mendapatkan penataan secara signifikan sesuai dengan tuntutan sebagai prasyarat untuk dijadikan media pariwisata yang menciptakan sebuah hunian Hotel Resort bintang 3 yang dilengkapi dengan fasilitas hiburan yang diselaraskan dengan potensi obyek wisata dan alam sekitar yang ada di Desa Bugbug, salah satu contohnya area pantai Bugbug itu sendiri. Sehingga sangat tepat lokasi Pantai Bugbug ini dijadikan Hotel Resort di Pantai Bugbug, kawasan wisata Candidasa, sebagai sebuah tempat destinasi wisata yang baru.

Hotel merupakan sebuah perusahaan yang bergerak di bidang jasa akomodasi serta pelayanan makan dan minum bagi para pelancong dengan imbalan pembayaran (Lawson, Davis, Crouter, \& O’Neill, 2013). Fungsinya sebagai akomodasi wisata, hotel dapat dikelompokkan sebagai berikut (Marlina, 2008):

a. Pengelompokan hotel menurut tujuan kedatangan tamu

- Business Hotel merupakan Hotel yang dirancang dengan tujuan memberi fasilitas untuk melakukan bisnis.

- Pleasure Hotel merupakan Hotel yang sebagian fasilitasnya ditujukan untuk memberi fasilitas kepada pengunjung untuk berekreasi.

- Country Hotel merupakan Hotel khusus untuk tamu antarnegara. Pemilihan lokasi ditentukan oleh Hotel ini dipilihkan di area pusat kota. 
- Sport Hotel Merupakan Hotel yang fasilitasnya dirancang untuk melayani pengunjung dengan tujuan berolahraga.

b. Berdasarkan fasilitas dan letaknya hotel resort dapat diklasifikasikan sebagai berikut:

- Beach Resort, Hotel Resort ini berada di daerah pantai dan menggunakan keindahan dan potensi alam pantai sebagai daya tariknya.

- Marina Resort, Hotel Resort ini berada di daerah pelabuhan, rancangan Resort ini memanfaatkan potensi dengan fasilitas dermaga dan kegiatan yang berhubungan dengan air.

- Mountain Resort, Hotel Resort ini berada di daerah pegunungan, yang digunakan sebagai ciri rancangan Resort.

- Health Resort And Spa Resort Hotel ini dibangun di daerah yang memiliki potensi alam yang dapat dimanfaatkan sebagai sarana penyehatan dan kebugaran melalui aktivitas spa.

- Condominium, Time Share And Residential Development Resort ini memiliki strategi pemasaran yang menarik yaitu menawarkan kamar Hotel ini disewa selama periode waktu yang ditentukan dalam kontrak dan biasaanya dalam jangka waktu yang panjang.

- All Suite-Hotels Resort jenis ini merupakan golongan Resort mewah, karena semua kamar yang disewakan dalam Hotel tersebut tergolong dalam kelas suite.

- Sight-Seeing Resort Hotel Resort jenis ini terletak di daerah yang memiliki potensi khusus atau tempat menarik seperti pusat perbelanjaan

Dalam perencaan Hotel Resort ini, civitas dibagi menjadi yaitu pengunjung (wisatawan domestik maupun mancanegara), pengelola, dan masyarakat lokal. Jenis hotel yang akan dirancang adalah berbintang 3 dengan jumlah kamar Hotel Resort yang akan disediakan dengan asumsi sebanyak 52 kamar termasuk 39 Kamar Standar, Room 7 kamar Deluxe Room dan 6 kamar Suite room. Perencaan ini menggunakan konsep dasar "rekreatif" dengan menfaatkan potensi wisata dan alam sekitar. Tema yang dipilih adalah Moderen tropis yang nanti akan di padukan dengan Arsitektur Bali. Site yang dipilih berada di
Pantai Bugbug dengan karakteristiknya sebagai berikut:

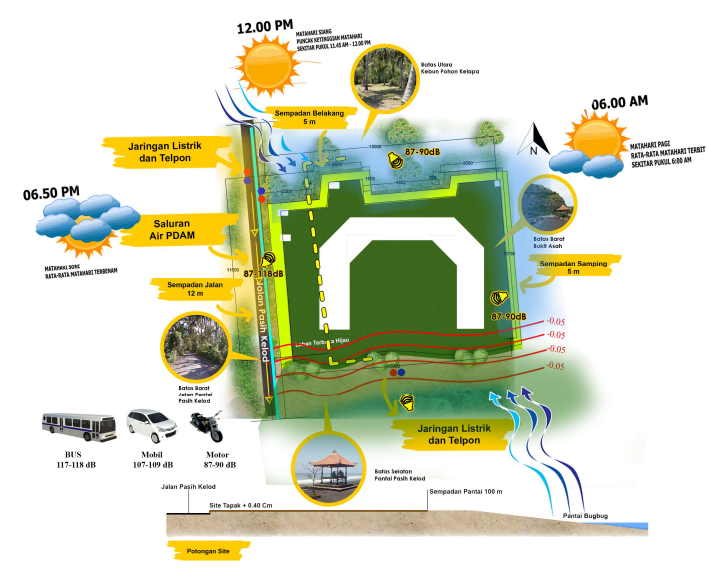

Gambar 1. Karakteristik site ( Sumber : Penulis, 2020)

\section{METODE PENELITIAN}

a. Metode pengumpulan data yang digunakan seperti, metode literatur yang dilakukan dengan cara mengambil data - data yang diperlukan dari literatur - literatur yang berkaitan. Metode Interview melakukan wawancara kepada penduduk setempat, dan melakukan wawancara dengan kelian desa.

b. Metode observasi yang dilakukan dengan cara melakukan pengamatan langsung di lapangan, Metoda dokumentasi yaitu pengambilan gambar untuk memperkuat dan memperjelas data - data yang sifatnya teoritis dengan cara mengambil foto secara langsung ke objek.

c. Metode pengolahan data kompilasi data yaitu pemilahan data yang kemudian disajikan dalam bentuk uraian deskripsi, table, grafik, sketsa, gambar dan foto.

d. Metode pembahasan yang digunakan seperti metode, Metode Komparatif yaitu melakukan suatu perbandingan data yang didapatkan dilapangan terhadap teori yang ada sesuai dengan obyek bahasan. Metode Analisis, yaitu data yang sudah 
dikompilasikan kemudian dianalisa untuk diketahui permasalahannya, Metode Sintesis, merupkan langkah mengintrgrasikan setiap unsure beserta faktor pengaruhnya dengan tujuan mencari jalan keluar terbaik bagi penyelesaian masalah.

\section{HASIL DAN PEMBAHASAN}

\section{Konsep Zoning}

Dari data analisis site dan dasar pertimbangan di atas maka penentuan zoning akan dibagi menjadi tiga zona yaitu zona servis, zona penunjang dan dan zona utama.

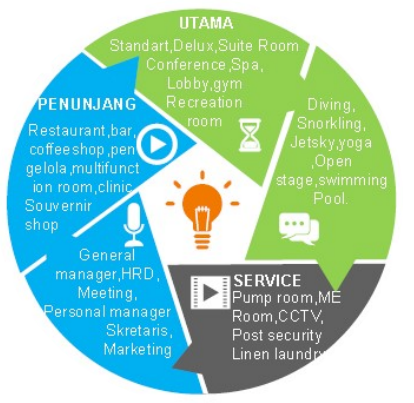

Gambar 2. Zoning

( Sumber : Penulis, 2020)

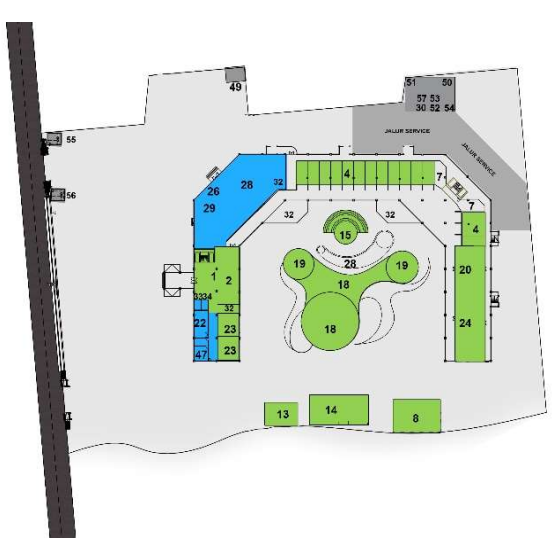

Gambar 3. Zoning site

( Sumber : Penulis, 2020)

\section{Konsep entrance}

Entrance merupakan jalur akses untuk memasuki suatu area atau bangunan. Sebagai ruang akses, tentunya entrance memerlukan suatu desain yang menarik dan mudah dikenali oleh pengguna ruang tersebut. Menarik dan mudah dikenali merupakan faktor yang perlu dipertimbangkan dalam perencanaan suatu entrance, sehingga menjadi vocal point dalam pencapaiannya (Faroga, 2014). Sebagai acuan untuk menentukan lebar, tinggi dan dimensi entrance menurut buku Standar Neufert mempunyai ukuran jenis kendaraan (Neufert, 2003):
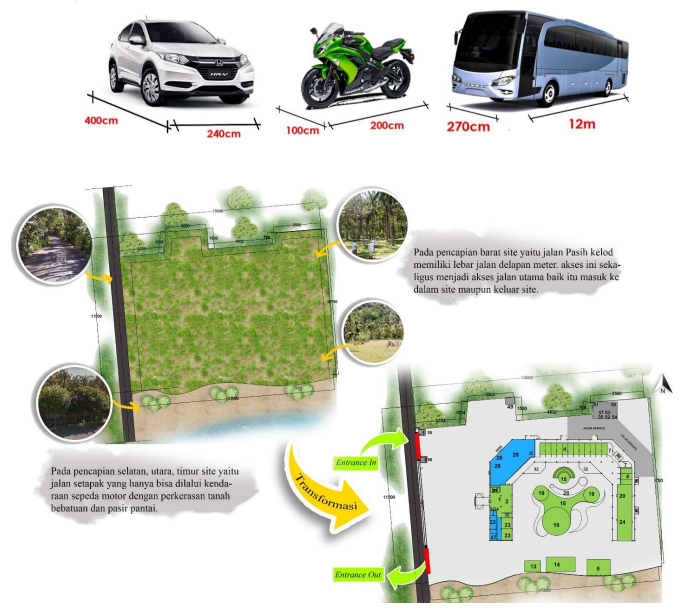

Gambar 4. Entrance site ( Sumber : penulis, 2020)

\section{Konsep massa}

Pola massa bangunan terdiri dari terpusat, linier, radial, cluster, dan konfigurasi massa grid (Ching, 2009). Konsep sistem massa bertujuan untuk mengetahui sistem (jumlah) massa dan pola massa yang digunakan pada site yang sesuai dengan fungsi yang akan diwadahi yaitu Hotel Resort, Konsep orientasi massa memiliki tujuan untuk menetukan arah orientasi bangunan sesuai dengan fungsi dan kebutuhan yang diwadahi serta sangat berkaitan dengan view yang akan dimanfaatkan yang ada pada site.

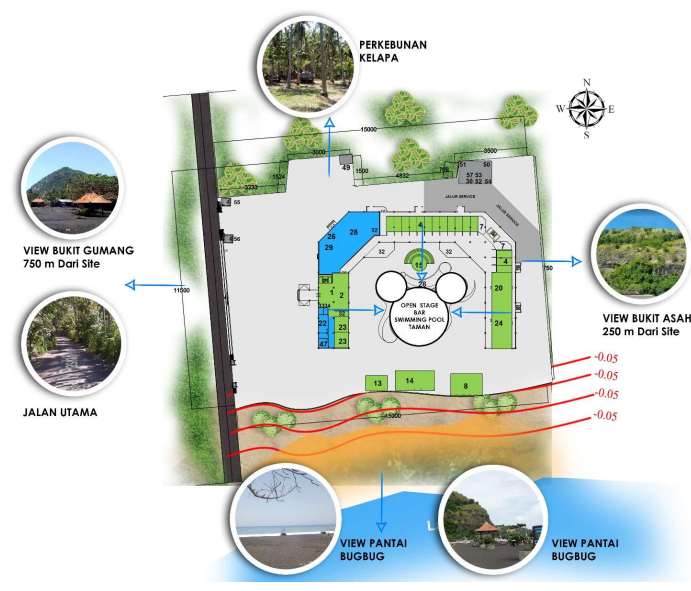

Gambar 5. Orientasi dan massa bangunan (Sumber : penulis, 2020) 


\section{Konsep sirkulasi massa}

Sirkulasi diartikan sebagai "tali" yang mengikat ruang-ruang dalam suatu bangunan sehingga saling berhubungan (Pynkyawati, Aripin, Iliyasa, \& Ningsih, 2014). Konsep sirkulasi massa adalah suatu sarana penghubung berbagai kegiatan aktivitas pengguna dalam sebuah site. Tujuan

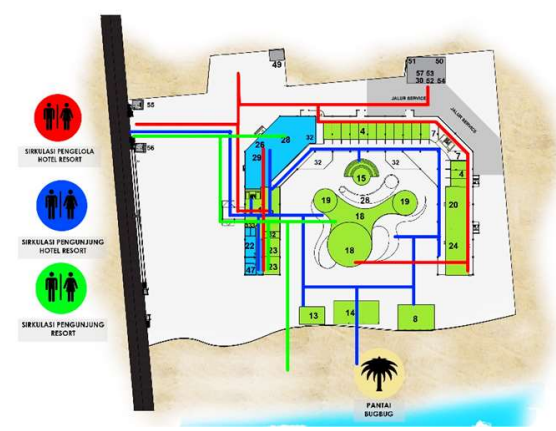

Gambar 6. Sirkulasi massa bangunan ( Sumber : penulis, 2020)

\section{Konsep ruang luar}

Dalam perencanaan ruang luar, aspek yang perlu diperhatikan adalah tema, gradasi, kontras dan keseimbangan (Wahyuni \& Qomarun, 2015). Sedangkan elemen-elemen dari ruang luar dapat dibagi menjadi dua yaitu hardscapes dan softscapes (Hakim, 2003). Penataan ruang luar atau Landscape akan diletakan beberapa jenis vegetasi (Softsscape) dan perkerasan (Hardscape) yang disesuaikan dengan fungsi vegetasi dan perkerasan tersebut.

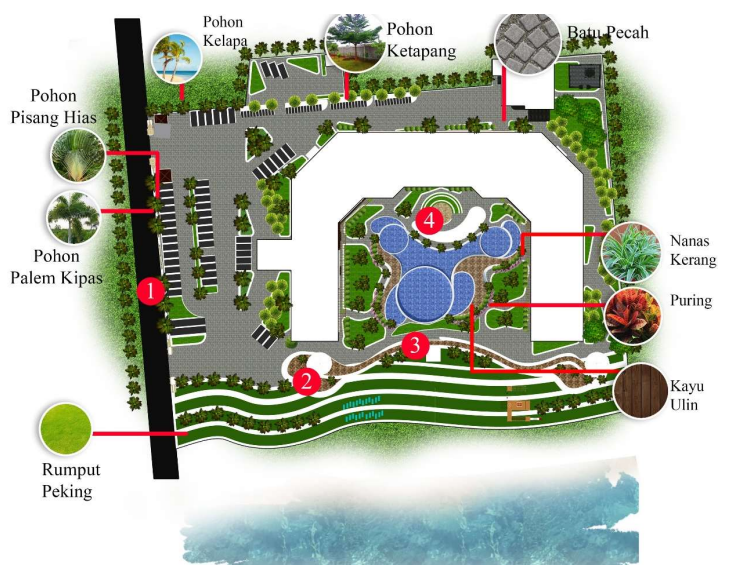

Gambar 7. Ruang luar

( Sumber : penulis, 2020)

\section{Konsep ruang dalam}

Konsep ruang dalam (interior) bertujuan untuk menentukan penataan desain ruang berdasarkan fungsi dan mencakup semua aspek keindahan, serta dapat memberikan kesan dan suasana yang sesuai dengan kegiatan hotel resort yang berlangsung di dalamnya.

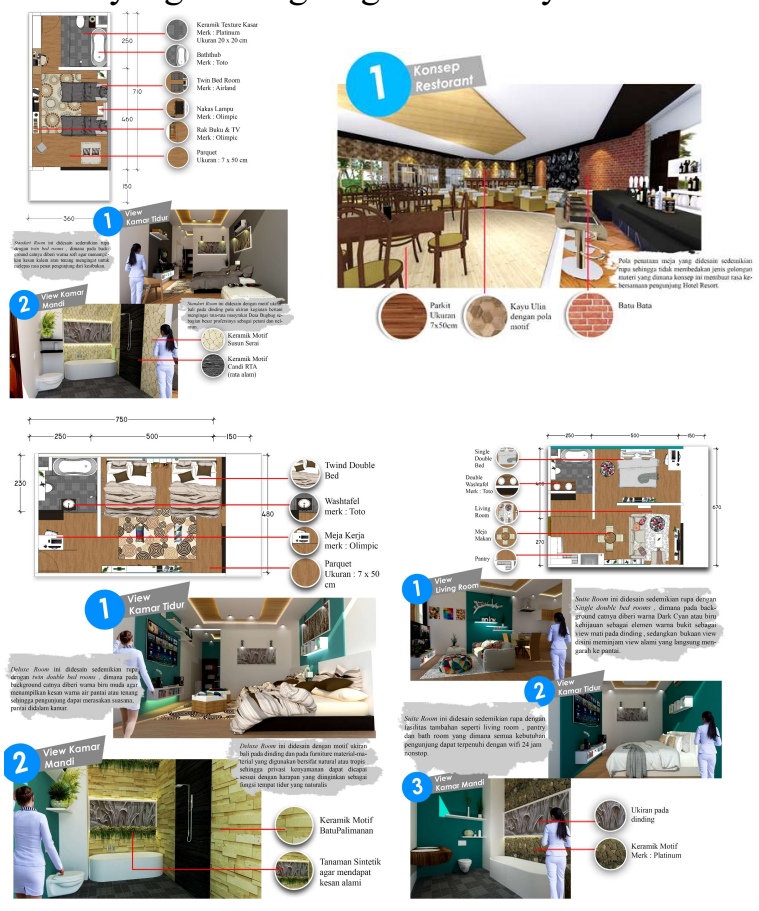

Gambar 8. Ruang dalam ( Sumber : penulis, 2020)

\section{Konsep tampilan bangunan}

Tujuan dari konsep tampilan bangunan yaitu untuk menentukan bentuk tampilan bangunan ornamen dan bahan, dasar pertimbangan tema rancangan yaitu Modern tropis yang dipadukan dengan Arsitektur Bali.

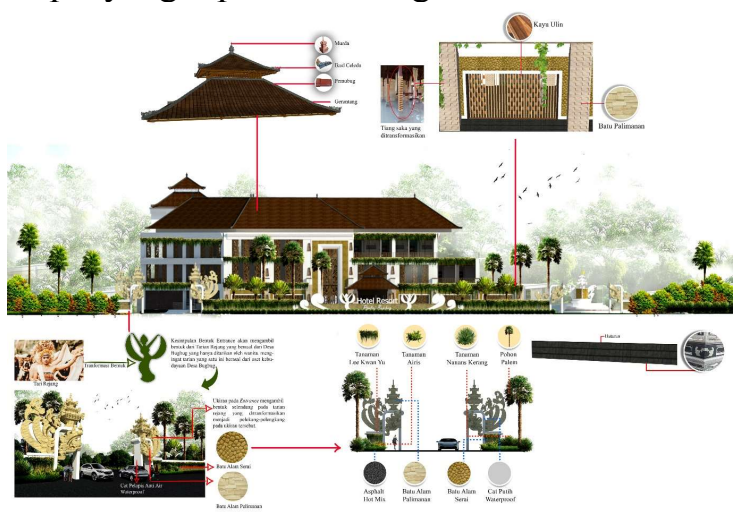

Gambar 9. Tampilan bangunan ( Sumber : penulis, 2020)

\section{SIMPULAN}

Konsep perencanaan bangunan yaitu konsep ruang dalam atau disebut interior bangunan 
yang menampilkan dimensi ruang, material dan fungsi ruang itu sendiri, dimana pada ruang dalam ini akan menghasilkan wujud tampilan bangunan atau wajah fasad exterior hotel resort ini dengan penerapan tema modern tropis yang dipadukan dengan Arsitektur Bali sehingga wujud tampilan hotel ini berciri khas Arsitektur Bali.

\section{DAFTAR PUSTAKA}

Ching, F. D. K. (2009). Arsitektur: Bentuk, Ruang dan Susunannya. Erlangga, Jakarta. https://doi.org/10.1177/10870547083262 71

Faroga, R. (2014). PERLETAKAN DAN BENTUK DESAIN MAIN ENTRANCE PADA BANGUNAN MAL TERBUKA (Studi Kasus: Mal Cihampelas Walk dan Mal Paris Van Java di Bandung). EJournal Graduate Unpar, 1(1).

Hakim, R. (2003). Komponen Perencanaan Arsitektur Lanskap. Jakarta: Balai Pustaka.

Lawson, K. M., Davis, K. D., Crouter, A. C., \& O'Neill, J. W. (2013). Understanding work-family spillover in hotel managers. International Journal of Hospitality Management.

https://doi.org/10.1016/j.ijhm.2012.09.00 3

Marlina, E. (2008). Panduan Perancangan Bangunan Komersil. Yogyakarta: Andi Offset.

Neufert, E. (2003). Data Arsitek Jilid 2. Erlangga.

Pynkyawati, T., Aripin, S., Iliyasa, E. R. I., \& Ningsih, L. Y. (2014). Kajian Efisiensi Desain Sirkulasi pada Fungsi Bangunan Mall Dan Hotel BTC. Jurnal Reka Karsa.

Wahyuni, E., \& Qomarun, Q. (2015).

IDENTIFIKASI LANSEKAP ELEMEN SOFTSCAPE DAN HARDSCAPE PADA TAMAN BALEKAMBANG SOLO. Sinektika: Jurnal Arsitektur. https://doi.org/10.23917/sinektika.v13i2. 755 